
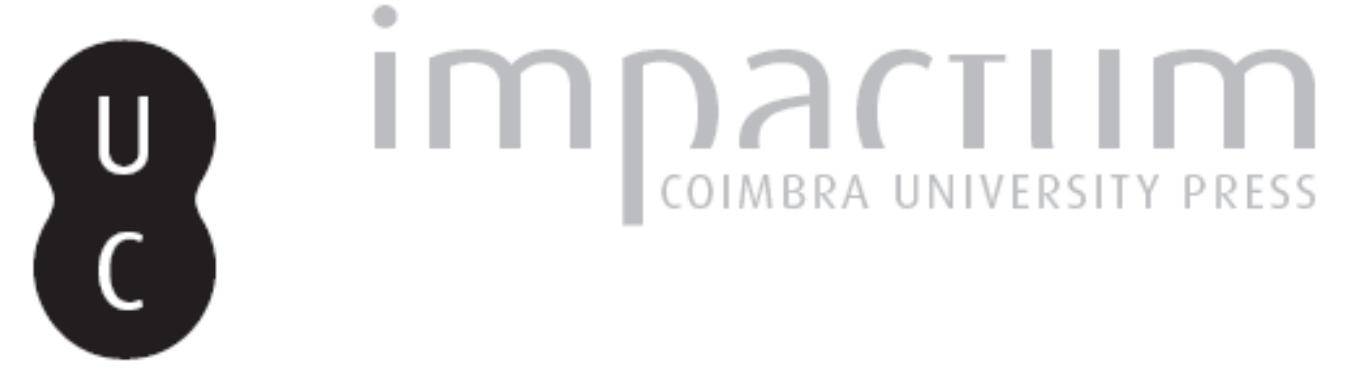

\title{
Um caso único em marcas de lucernas: uma Figlina em Bracara Augusta documentada pela oficina de Lucretius
}

\author{
Autor(es): $\quad$ Morais, Rui
}

Publicado por: Faculdade de Letras da Universidade de Coimbra

URL

persistente:

URI:http://hdl.handle.net/10316.2/37710

DOI:

DOI:http://dx.doi.org/10.14195/1647-8657_43_12

Accessed : $\quad$ 26-Apr-2023 13:33:36

A navegação consulta e descarregamento dos títulos inseridos nas Bibliotecas Digitais UC Digitalis, UC Pombalina e UC Impactum, pressupõem a aceitação plena e sem reservas dos Termos e Condições de Uso destas Bibliotecas Digitais, disponíveis em https://digitalis.uc.pt/pt-pt/termos.

Conforme exposto nos referidos Termos e Condições de Uso, o descarregamento de títulos de acesso restrito requer uma licença válida de autorização devendo o utilizador aceder ao(s) documento(s) a partir de um endereço de IP da instituição detentora da supramencionada licença.

Ao utilizador é apenas permitido o descarregamento para uso pessoal, pelo que o emprego do(s) título(s) descarregado(s) para outro fim, designadamente comercial, carece de autorização do respetivo autor ou editor da obra.

Na medida em que todas as obras da UC Digitalis se encontram protegidas pelo Código do Direito de Autor e Direitos Conexos e demais legislação aplicável, toda a cópia, parcial ou total, deste documento, nos casos em que é legalmente admitida, deverá conter ou fazer-se acompanhar por este aviso.

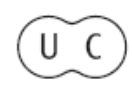


CONIMBRIGA

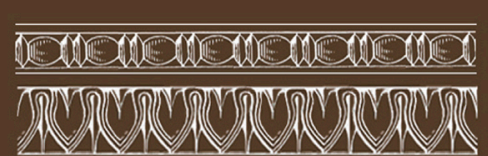

INSTITUTO DE ARQUEOLOGIA

VOLUME XLIII - 2004

FACULDADE DE LETRA

UNIVERSIDADE DE COIMBRA 
RUI MORAIS

Assistente da Universidade do Minho

\section{UM CASO ÚNICO EM MARCAS DE LUCERNAS}

- UMA FIGLINA EM BRACARA AVGVSTA DOCUMENTADA

PELA OFICINA DE LVCRETIVS

"Conimbriga" XLIII (2004) p. 227-240

RESUMO: Estuda-se um conjunto de marcas assinadas por Lucretius presentes em lucernas fabricadas na cidade romana de Bracara Augusta, do tipo Loeschcke V e X e Dressel 20 e 28.

Atendendo à unicidade e peculiaridade daquele tipo de assinaturas, recorreu-se a outras situações documentadas no âmbito de outras cerâmicas romanas.

Como resultado desta interpretação, propõe-se que estas possam documentar o estatuto municipal da cidade e a existência de uma figlina, interpretada como zona de barreiros e de produção de cerâmica.

Summary: A set of stamps signed by Lucretius, present in oil lamps produced in the Roman city of Bracara Augusta, belonging to Loeschcke V and X and Dressel 20 and 28 types, is studied.

Taking in account the uniqueness and peculiarity of that type of signatures, we resorted to additional documented sources in the realm of other Roman ceramics.

As a result of this interpretation, is proposed that these signatures may be used as a proof of the municipal statute of the city and of the existence of a figlina, interpreted as a clay and ceramic production area. 
(Página deixada propositadamente em branco) 


\section{UM CASO ÚNICO EM MARCAS DE LUCERNAS - UMA FIGLINA EM BRACARA AVGVSTA DOCUMENTADA PELA OFICINA DE LVCRETIVS}

No conjunto das marcas de lucernas recolhidas na cidade romana de Bracara Augusta, destaca-se um conjunto de lucernas assinadas por Lucretius, às quais se atribui, com segurança, uma origem bracarense, levando em consideração o tipo de fabrico e o número de marcas encontradas e sua variabilidade terminológica.

Destas constam, pelo menos, 5 assinaturas diferentes (a maior parte das quais encontradas na cidade), presentes numa variante regional do tipo Loeschcke V, datada de 75/80 a inícios de Adriano, e noutras variantes regionais do tipo Dressel 20 e Loeschcke X, datáveis de entre os finais do século I d. C. e a $1^{\text {a }}$ metade do século II.

\begin{tabular}{|c|c|c|c|c|c|c|}
\hline & TIPO LOESCHCKE V & TIPO DRESSEL 20 & TIPO LOESCHCKE X & $\begin{array}{c}\text { TIPO } \\
\text { INDETERMINADO }\end{array}$ & TIPO DRESSEL 28 & TOTAL \\
\hline BRAGA & EX OI/ LVCRETI & $\begin{array}{l}\text { EXO / L.V.CR'ETI } \\
\text { EX OI / LVCRETI ( } 2 \text { ex.) } \\
{[\ldots] /[\ldots] \text { RETI }} \\
{[\ldots] /[\ldots] \text { ETI }} \\
{[\ldots] /[\ldots] I ?}\end{array}$ & 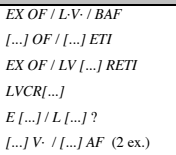 & & $E O X / L V C R E[\ldots]$ & c. 15 \\
\hline BRITEIROS & & & $L \cdot V \cdot / B M$ & & & 1 \\
\hline VILA DO CONDE & & EX O F/LVCRET & & & & 1 \\
\hline $\begin{array}{l}\text { FONTE } \\
\text { DO MILHO }\end{array}$ & & LVCRETI & & & & 1 \\
\hline LUGO & & & $E X \cdot O F / L \cdot V \cdot / B \cdot A \cdot F$ & & & 1 \\
\hline CACABELOS & & & EX OF / LVCRETI / GMBF & LVCRETI' & & 2 \\
\hline ASTORGA & & EX OF/LVCRETI & & & & 1 \\
\hline CONÍMBRIGA & & & & {$[\ldots] / L V[\ldots] ?$} & & 1 \\
\hline TOTAL & 1 & c. 9 & c. 10 & 2 & 1 & c. 23 \\
\hline
\end{tabular}

Proveniência e quantidade de lucernas com a assinatura de LVCRETIVS

Neste conjunto destacam-se as marcas $E X \cdot O F / L \cdot V \cdot / B \cdot A \cdot F, E X$ $O F / L V C R E T I / G M B F$ e $L \cdot V \cdot / B M$ assinadas em lucernas do tipo Loes-

1 Apenas se conhece a publicação da marca. 
chcke $\mathrm{X}$, pelo facto de possuírem algumas letras associadas ao nome Lucretius, cuja interpretação nos parece significativa.

Atendendo à unicidade e peculiaridade deste tipo de assinaturas, recorremos a outras situações documentadas no domínio das cerâmicas romanas que pudessem permitir uma leitura sugestiva destas marcas.

Das situações observadas salientamos o papel das cidades nas actividades produtivas, não só como centros de tráfego e redistribuição, mas também com responsabilidades "empresariais" e comerciais associadas. Estes exemplos estão patentes em marcas de terra sigillata com as siglas C. I. A. E. F. documentadas por F. Mayet (1984: 197-198) no Museu de Mérida, que, em conjunto com marcas idênticas encontradas numa tégula ${ }^{2}$ e num tubo de chumbo ${ }^{3}$ aí depositados e numa interessante inscrição localizada em Cabezo de Pilas, sugeriram à autora a possibilidade de se tratar de siglas correspondentes à própria capital lusitana: C(olonia) I(ulia) A(ugusta) E(merita).

Segundo a autora, estes três produtos utilizados pelos habitantes de Mérida possuem uma marca idêntica às iniciais da cidade, o que pressupõe, pelo menos no caso das marcas em terra sigillata (cujas análises inequivocamente se atribuem ao ateliê de Bezares), que a cidade de Mérida recebia encomendas oficiais dos artesãos de Tritium (a menos que a cidade não possuísse ela própria uma oficina neste vasto sector artesanal $)^{4}$.

Para a letra F presente no final das marcas em sigillata, esta autora sugere, num artigo conjunto com Robert Étienne (1984: 164), que, à semelhança de determinadas estruturas de produção em tijolos romanos, esta sigla possa corresponder a "figlinae".

Mais significativa é, porém, a informação que nos proporcionam as ânforas. Aqui interessam-nos, em particular, as variadas referências

2 No actual território português temos os exemplos de lateres recolhidos nas cidades romanas de Conimbriga e Seilum com a menção $\mathrm{R}(e s) \mathrm{P}($ ublica) seguida de uma sigla relativa ao nome da cidade e do povoado mineiro de Três Minas (Vila Pouca de Aguiar), com a marca AFL, cujo desdobramento mais provável será A(quae) FL(aviae) (vid. Wahl, 1988: 234-235; Alarcão, 1990: 415, Fernandes e Ferreira, 2002: 257-267).

3 O hábito de assinalar o nome da cidade em canalizações de chumbo está bem documentado em exemplares recolhidos em Itália e na região de Viena (Isère) (Hansen, 1986: 78, Fig. 41; 79 ss).

4 Outras duas marcas com as mesmas letras são dadas como provenientes de Tricio (Garabito, 1978: 131, n. ${ }^{\circ}$ 2) e Bezares (Mezquíriz, 1975: 232, Fig. 1, n. ${ }^{\circ}$ 6; 240; cf. proveniência em Garabito, 1978: 131, n. ${ }^{\circ}$ 3). 
aos proprietários expressas segundo a fórmula tria nomina associados a um nome geográfico, seja ele cidade ou conventus, ou o nome da figlina, associando ou não membros da mesma família. Aduzam-se, como testemunhos das primeiras, as marcas $Q$. F(uluius) S(abinus) Cuf(iense) Fan(ni) Fort(unati) col(onia) Hadr(umento) e Ex o(fficinis) Iuli Honora(ati) $P$ (rovinciae) M(auretaniae) T(ubusuctu); e, como testemunho das segundas, as marcas Gemellian(a) e II Aur(eli) Heraclae Pat(er) et fil(ius) [ex] f(iglinis) Bar(bensis) (vid. Beltrán-Lloris, 1990: 27).

Ainda que deveras sugestivos, estes exemplos não nos pareciam, todavia, totalmente esclarecedores quando comparados com as marcas das lucernas em análise. De facto, ainda que pudéssemos aceitar que as letras $B A F, B F$ ou simplesmente $B$, correspondessem a Bracara Augusta figlinis, a sua associação com outras letras não permitia compreender o verdadeiro papel da cidade neste processo produtivo. Teria a cidade de $\mathrm{Bra}$ cara Augusta directamente funcionado como uma espécie de empresa comercial que tinha a seu cargo diferentes oficinas de oleiros?

Neste ponto é preciosa a informação proporcionada por determinadas marcas recolhidas em tijolos, dado possuírem uma elaborada e valiosa informação sobre o modo como as indústrias de olaria poderiam estar organizadas.

Dos exemplos que tivemos ensejo de observar destacam-se, entre outros, as seguintes marcas (Helen, 1975: 9; 49; 53; Peacock, 1982: 133):

\section{$306 \mathrm{c}]$ \\ C.SATRINI. COMMVN/DE. FIGLINIS/MARCIANIS [CIL}

C.CAL.FAVORIS/EX.FIGLI MARCIANIS/IMP.CAES NER.TRA.AVG [CIL 312]

EX·PR $\cdot \mathrm{M} \cdot \mathrm{A} \cdot \mathrm{V} \cdot \mathrm{OFFIC}$ ANNI ZOS FIG CERM $\cdot \mathrm{PONT} \cdot \mathrm{ET}$ ACIL [CIL 245]

Segundo um estudo realizado por Tapio Helen sobre estas e outras marcas em tijolos do século I e II, o termo figlinae presente nestas marcas deve ser interpretado como zona de barreiras e de produção (1975: 45).

Para esta autora devem distinguir-se, no entanto, dois tipos de marcas características do século I e século II, respectivamente.

Nas marcas do século I - aqui exemplificada pela primeira marca acima referida - o nome de figlina figura apenas como marca de qualidade da mesma, como zona de boas argilas, sendo desnecessário mencionar o dono da figlina. 
Nas marcas do século II - aqui exemplificadas pelas restantes duas marcas - a palavra figlina adquire uma nova função: enunciar o nome do dono da figlina, o dominus.

Entre outras possibilidades, se levarmos em consideração a proposta desta autora para as marcas em tijolos e se a aplicarmos às lucernas em estudo podemos sugerir a seguinte leitura:

$\mathrm{EX} \cdot \mathrm{OF} / \mathrm{L} \cdot \mathrm{V} \cdot \mathrm{B} \cdot \mathrm{A} \cdot \mathrm{F}$ (recolhida em Braga e Lugo) ex of(ficina)/Lu(creti)/(ex) f(iglinis) B(racara) A(ugusta)

EX OF/LVCRETI/GMBF (recolhida em Cacabelos) ex of(ficina)/Lucreti/(ex) f(iglinis) B(racara) [Augusta]; $G(?) M(?)$

L V/BM (recolhida na Citânia de Briteiros) (ex officina) Lu(creti)/(ex figlinis) B(racara)[Augusta]; M(?)

No primeiro caso estaríamos perante uma marca datável dos finais do século I na qual o nome da figlina Bracara Augusta apenas estava presente como marca de qualidade. Sendo, como se depreende, desnecessário mencionar o dono da figlina, é possível que nesse local existissem várias oficinas independentes administrativamente, estando apenas referido o nome dos oleiros responsáveis por cada produção. Neste caso, a palavra figlina surge qualificada por um adjectivo específico que indica o seu nome.

Nos casos seguintes, parece estarmos perante marcas enquadráveis no século II. Aqui, se analisarmos a forma original do texto, a palavra figlina parece adquirir uma nova função quando comparada com a marca acima referida datável do século I: nestas distingue-se o nome de uma segunda pessoa através das siglas $G M$ ou simplesmente $M$.

Nestes casos as marcas aparecem sem um adjectivo que expressa o nome da figlina: esta agora é necessária para enunciar o seu dono, o dominus. O dominus é a pessoa cujo nome é usado no texto como atributo genitivo da palavra figlinae; isto é a pessoa que se declara na marca ser o possuidor da figlina. Trata-se de marcas binominais nas quais o nome do dominus e do officinator surge naturalmente, sendo que cada qual teria uma posição diferente no processo e organização da produção.

À semelhança do que sucedia com as marcas em tijolo (vid. Helen, 1975: 130), o officinator (Lucretius) seria uma pessoa livre e indepen- 
dente na lei do dominus (GM; M), ainda que seja plausível uma posição social diferenciada.

Como vimos, o dominus seria o dono da terra na qual e da qual as lucernas eram feitas. Nesta relação é possível que - e de novo à semelhança do sucedido na produção de tijolos (vid. id. ibidem) -, o contrato entre estes intervenientes fosse locatio-conductio, estando o dominus na posição de locator e o officinator na posição de conductor.

Se encararmos a verosimilhança desta proposta poder-se-á supor que esta figlina bracaraugustana continha várias oficinae nas quais as lucernas e outros produtos cerâmicos eram feitos a partir do barro aí extraído5. Dos vários officinatores directamente ligados à produção de lucernas entretanto documentados na cidade (Publius Domitius, Octavi, Bassi, Mic(cio?), Lucretius seria, pela quantidade e diversidade de lucernas e respectivas marcas, um dos principais produtores da cidade.

Segundo esta hipótese, poder-se-á ainda supor que esta figlina bracaugustana não funcionou como uma unidade administrativa nem com uma unidade de produção mas simplesmente uma entidade territorial.

De tudo isto o que podemos certamente aceitar é que à dificuldade de leitura destas marcas corresponde um texto simples que as pessoas para quem a mensagem era destinada a percebiam a partir de um texto muito abreviado, no qual o nome do officinator, o lugar de manufactura (nome da figlina) e o nome do dominus (neste caso de modo abreviado) eram transmitidos. Neste ponto a ordem das palavras interessava pouco e o final das declinações não importavam nada.

\section{CATÁLOGO}

EsT. I

EX OI/LVCRETI

1 - Lucerna de volutas. Corpo piriforme e perfil trococónico. Orla larga, descaída para o exterior, não decorada. A orla é separada do disco por duas molduras entre três caneluras. Disco levemente cavado, com orifício de alimentação lateral, ornamentado com uma Vitória alada, à esquerda, sobre um globo e segurando na mão direita um escudo. O rostrum está fragmentado e en-

5 No caso da cidade romana de Bracara Augusta a região do Prado/Ucha, situada a cerca de $14 \mathrm{~km}$, foi seguramente um local para a extracção de barreiras e, quiçá, centro de estabelecimento de olarias destinadas ao abastecimento da cidade e respectiva região, situação, alias, comprovada desde os idos medievais até à data. 
cimado por duas volutas simples. Asa fina e perfurada. Fundo ligeiramente alteado definido por uma moldura e uma canelura concêntrica. Marca: EX OI/LVCRETI em relevo com caracteres do tipo actuário, com forte influência da escrita cursiva. A irregularidade é geral: a inclinação, o tamanho e os espaços que separam as letras. Saliente-se a ausência de travessões na letra F do formulário, a letra L com travessão estreito e a letra T de maiores dimensões que as restantes. Tipo: Lucerna de volutas (Loeschcke V). Produção: Local. Cronologia: Fins do reinado de Cláudio a inícios do século II (auge: c. de 75/80 até reinado de Adriano). Proveniência: Braga sem contexto (n..$^{\circ}$ inventário: 2002-2186).

\section{EST. II \\ EX O/LVCRETI}

2 - Lucerna de disco. Corpo circular. Orla lisa muito larga, descaída para o exterior. Bico curto e arredondado com a parte superior plana, separado do disco por um segmento de recta constituído por uma moldura, limitado por uma pequena protuberância circular em cada uma das extremidades. O disco côncavo é circundado por uma fina moldura e decorado com os bustos de Castor e Polux, entre os quais se situa o orifício de alimentação. Asa perfurada e fundo alteado. Marca: EX O/LVCRETI, em relevo com caracteres do tipo actuário, com forte influência da escrita cursiva. A irregularidade é geral: a inclinação, o tamanho e os espaços que separam as letras. Saliente-se a ausência da letra $\mathrm{F}$ do formulário, a grandeza excessiva da letra $\mathrm{L}$ e a existência de três pontos de separação no nome do oleiro. Tipo: Lucerna de disco (Dressel 20). Produção: Local. Cronologia: Finais do século I/1ª metade do século II. Proveniência: Necrópole da Via XVII (núcleo de Carlos Amarante) (n. ${ }^{\circ}$ inventário: 1991-0607).

\section{EST. III \\ EX OI/LVCRETI}

3 - Fragmento de lucerna de disco. Corpo circular e secção troncocónica. Orla lisa, muito larga, inclinada para o exterior. Asa elevada e perfurada e fundo plano que assenta numa coroa circular definida por uma moldura concêntrica. Marca: EX OI/LVCRETI em relevo demarcada por duas linhas auxiliares em forma de grossa moldura. Os caracteres são do tipo actuário, com forte influência da escrita cursiva. Apesar destas linhas auxiliares a irregularidade é geral: a inclinação, o tamanho e os espaços que separam as letras. Saliente-se a ausência de travessões na letra $F$ do formulário e representação da letra V em forma de Y grego. Tipo: Lucerna de disco (Dressel 20). Produção: Local. Cronologia: Finais do século I/1 ${ }^{\underline{a}}$ metade do século II. Proveniência: Colina da Cividade (n. ${ }^{\circ}$ inventário: 1991-1529). 


\section{EX OI/LVCRETI}

$4-I d$. Fundo com início de arranque do rostrum. Fundo plano que assenta numa coroa circular definida por uma moldura concêntrica. Marca: EX OI/LVCRETI em relevo com caracteres do tipo actuário, com forte influência da escrita cursiva. A irregularidade é geral: a inclinação, o tamanho e os espaços que separam as letras. Saliente-se a irregularidade da letra E e a ausência de travessões na letra F do formulário. Tipo: Lucerna de disco (Dressel 20). Produção: Local. Cronologia: Finais do século I/1 $1^{\underline{a}}$ metade do século II. Proveniência: Colina da Cividade (n. ${ }^{\circ}$ inventário: 1991-1527).

\section{LVCRETI?}

5 - Id. Fundo plano que assenta numa coroa circular definida por uma moldura concêntrica. Marca: LVCRETI ?, fragmentada à esquerda. Tipo: Lucerna de disco (Dressel 20)? Produção: Local. Cronologia: Finais do século I/1 ${ }^{\underline{a}}$ metade do século II. Proveniência: Colina da Cividade ( . $^{\circ}$ inventário: 2003-1370).

\section{LVCRETI}

$6-I d$. Infundibulum e fundo plano que assenta numa coroa circular definida por uma moldura concêntrica. Marca: LVCRETI fragmentada à esquerda, inserida numa cartela rectangular e em relevo. Tipo: Lucerna de disco (Dressel 20)? Produção: Local. Cronologia: Finais do século I/1ª metade do século II. Proveniência: Fujacal (n. ${ }^{\circ}$ inventário: 1996-0900).

\section{LVCRETI}

7 - Id. Infundibulum e fundo plano que assenta numa coroa circular definida por uma moldura concêntrica. Marca: LVCRETI ilegível à esquerda e com incisões muito ténues, sendo apenas visível com o auxílio da lupa de mão e sob determinados ângulos. Tratar-se-ia muito provavelmente de um molde excessivamente gasto. Tipo: Lucerna de disco (Dressel 20)? Produção: Local. Cronologia: Finais do século I/1 $\stackrel{\text { a }}{ }$ metade do século II. Proveniência: Braga sem contexto (n. ${ }^{\circ}$ inventário: 2002-2247).

\section{Est. IV}

\section{EX OF/LVCRETI}

8 - Lucerna de Canal. A orla, larga e muito inclinada para o exterior, está decorada com pequenas pérolas em relevo dispostas ao longo de uma alta e grossa moldura que separa a orla do disco. Disco côncavo preenchido com a decoração de um cavalo em queda. Dado apenas se ter conservado a parte traseira deste animal não sabemos se este estava representado sozinho ou incluído num grupo específico com a representação de Amazonas (vid. Bailey, 1980: 39-40; 79; Q 779, Q1068; 137-138). Fundo alteado rodeado por três molduras 
concêntricas. Marca: EX OF/LVCRETI fragmentada à esquerda e em relevo com caracteres do tipo actuário. Da parte conservada saliente-se a letra $\mathrm{O}$ quase circular e os travessões da letra F ligeiramente subidos. Tipo: Lucerna de canal ou Firmalampen (Loeschcke X). Produção: Local. Cronologia: Finais do século I/meados do século II. Proveniência: Colina da Cividade (n. ${ }^{\circ}$ inventário: 1991-1533).

\section{LVCR ETI}

9 - Id. Infundibulum e fundo alteado rodeado por três molduras concêntricas muito bem definidas. Marca: LVCR ETI em relevo com caracteres do tipo actuário e com alguma irregularidade no que respeita à inclinação das letras. Tipo: Lucerna de canal ou Firmalampen (Loeschcke X). Produção: Local. Cronologia: Finais do século I/meados do século II. Proveniência: Sé (n. ${ }^{\circ}$ inventário: 2002-2303).

\section{EX OF/LV CRETI}

10 - Id. Corpo piriforme e perfil troncocónico. Infundibulum com início de rostrum que forma com este um ângulo obtuso. Fundo alteado rodeado por três molduras concêntricas muito bem definidas. Marca: EX OF/LV CRETI em relevo com caracteres do tipo actuário, com forte influência da escrita cursiva. A irregularidade é geral: a inclinação, o tamanho e os espaços que separam as letras. Ausência por fractura da letra $\mathrm{C}$ e parte da letra R. Da parte conservada saliente-se a letra $\mathrm{O}$ quase circular e o travessão superior da letra $\mathrm{F}$ ligeiramente subido. Tipo: Lucerna de canal ou Firmalampen (Loeschcke X). Produção: Local. Cronologia: Finais do século I/meados do século II. Proveniência: Maximinos (n. ${ }^{\circ}$ inventário: 1991-1530).

\section{EsT. V}

\section{EX OF/LVCRETI ?}

11 - Id. Fundo alteado rodeado por duas molduras concêntricas que incluem uma marca. Marca: EX OF/LVCRETI ? em relevo, fracturada na sua quase totalidade. Tipo: Lucerna de canal ou Firmalampen (Loeschcke X)? Produção: Local. Cronologia: Finais do século I/meados do século II. Proveniência: Edifício Cardoso da Saudade (n. ${ }^{\circ}$ inventário: 2002-2236).

\section{EX OF/LV/BAF}

12 - Id. Infundibulum e fundo alteado rodeado por duas molduras concêntricas. Marca: EX OF/LV/BAF em relevo. Dado o excessivo estado de fragmentação apenas é perceptível a pontuação a seguir à letra $\mathrm{V}$ (praticamente ausente por fractura) e a letra F final. Tipo: Lucerna de canal ou Firmalampen (Loeschcke X)? Produção: Local. Cronologia: Finais do século I/meados do século II. Proveniência: Colina da Cividade (n. ${ }^{\circ}$ inventário: 1991-1566). 


\section{$\mathrm{EX} \mathrm{OF/LV/BAF}$}

13 - Id. Infundibulum e fundo alteado rodeado por duas molduras concêntricas. Marca: EX OF/LV/BAF em relevo. Dado o excessivo estado de fragmentação apenas é perceptível a última letra da marca com forte influência da letra cursiva. Tipo: Lucerna de canal ou Firmalampen (Loeschcke X)? Produção: Local. Cronologia: Finais do século I/meados do século II. Proveniência: Fujacal (n. ${ }^{\circ}$ inventário: 2003-1211).

\section{EsT. VI}

\section{$\mathrm{EX} \mathrm{OF/LV/BAF}$}

14 - Lucerna de canal. Corpo piriforme e perfil troncocónico. O infundibulum acompanha a forma circular do disco, formando com o bico tubular um ângulo obtuso. A extremidade do rostrum está unida ao disco por um canal de lados paralelos formados por uma moldura contínua que rodeia o disco e o orifício de iluminação. A orla larga é ornamentada por duas molduras transversais. Asa perfurada e fundo plano, ligeiramente alteado, rodeado por uma moldura concêntrica. Marca: EX OF/LV/BAF em relevo com caracteres do tipo actuário, com forte influência da escrita cursiva. A irregularidade é geral: a inclinação, o tamanho e os espaços que separam as letras. Saliente-se, entre outros aspectos, a letra $\mathrm{F}$ do formulário com os travessões ligeiramente subidos; letra V muito aberta e esvasada e a existência de pontuação entre as letras L e V. Tipo: Lucerna de canal ou Firmalampen (Loeschcke X)? Produção: Local. Cronologia: Finais do século I/meados do século II. Proveniência: Termas (n. ${ }^{\circ}$ inventário: 1991-1640).

\section{EST. VII}

\section{EO X/LVCRETI}

15 - Lucerna de disco. Corpo circular. Orla arredondada e larga, ligeiramente inclinada para o exterior, ornamentada com peltas. A transição para o disco, côncavo, faz-se por duas grossas molduras que definem duas caneluras concêntricas. O disco é liso com um grande orifício de alimentação central. Rostrum curto, fracturado, com parte do orifício de iluminação, com a parte superior em forma de coração encimada por um dos dois meios círculos impressos. Asa elevada e perfurada, fracturada. Sinais evidentes de utilização na zona do rostrum. Marca: EO X/LVCRETI em relevo muito pouco acentuado com caracteres do tipo actuário, com forte influência da escrita cursiva. A irregularidade é geral: a inclinação, o tamanho e os espaços que separam as letras. Saliente-se a posição incorrecta da letra $\mathrm{O}$ do formulário, situada a seguir à letra E e antes da letra X. Tipo: Lucerna de disco (Dressel 28). Produção: Local. Cronologia: $2^{\mathrm{a}}$ metade do século II/século III. Proveniência: Termas (n. ${ }^{\circ}$ inventário: 1991-1539). 


\section{EsT. VIII}

\section{EX OF/LVCRETI}

16 - Lucerna de disco. Corpo circular e perfil troncocónico. Orla larga e lisa, inclinada para o exterior, separada do disco por duas molduras que definem uma canelura concêntrica. Disco côncavo ornamentado com uma coroa possivelmente constituída por folhas de oliveira. Rostrum arredondado com orifício de iluminação. Asa perfurada, fracturada e fundo alteado que assenta em três molduras concêntricas. Marca: EX OF/LVCRETI em relevo com caracteres são do tipo actuário, com forte influência da escrita cursiva. A irregularidade é geral: a inclinação, o tamanho e os espaços que separam as letras. Saliente-se a ausência da letra I. Tipo: Lucerna de disco (Dressel 20). Produção: Local. Cronologia: Finais do século I/1ª metade do século II. Proveniência: Vila do Conde (Necrópole Romana) (n. ${ }^{\circ}$ inventário: 1991-2340).

\section{Est. IX}

\section{$\mathrm{L} \mathrm{V} / \mathrm{BM}$}

17 - Lucerna de canal. Corpo piriforme e perfil troncocónico. O infundibulum acompanha a forma circular do disco, formando com o bico tubular um ângulo obtuso. A extremidade do rostrum está unida ao disco por um canal de lados paralelos formado por uma moldura contínua que rodeia o disco e o orifício de iluminação. A orla larga é ornamentada por duas molduras transversais. Asa perfurada e fundo alteado com marca rodeado por uma moldura concêntrica. Marca: L V/BM em relevo com caracteres são do tipo actuário, com forte influência da escrita cursiva. A irregularidade é geral: a inclinação, o tamanho e os espaços que separam as letras. Saliente-se a existência de dois pontos de separação no nome do oleiro e a representação da letra $\mathrm{V}$ em forma de Y grego. Tipo: Lucerna de canal ou Firmalampen (Loeschcke X). Produção: Local. Cronologia: Finais do século I/meados do século II. Proveniência: Citânia de Briteiros (n. ${ }^{\circ}$ inventário: 2002-2337).

\section{REFERÊNCIAS BIBLIOGRÁFICAS}

AlarCão 1990: JoRge AlarCÃo - “A produção e a circulação de produtos”, Nova História de Portugal, vol. I (Portugal das Origens à Romanização), Lisboa, 409-441. AlmeIdA 1974: CARlos Alberto Ferreira DE AlmeIDA - "Necrópole Galaico-Romana de Vila do Conde", Sep. da "Revista da Faculdade de Letras" da Universidade do Porto, Série História, vol. IV (1973), Porto, 1974.

BELCHIOR 1969: C. BELCHIOR - Lucernas romanas de Conimbriga, Museu Monográfico de Conimbriga, Coimbra, 1969. 
Beltrán-Lloris 1990: M. Beltrán-Lloris - Guía de la Cerámica Romana, Libros Pórtico, Zaragoza, 1990.

Cortez 1951: Fernando Russell Cortez - "As Escavações Arqueológicas do "Castellum" da Fonte do Milho. Contributo para a Demogenia Duriense", Separata dos Anais do Instituto do Vinho do Porto (1. ${ }^{\circ}$ vol.), Edição do Instituto do Vinho do Porto, Porto, 1951.

Delgado 1984: Manuela Delgado - "Sepultura romana encontrada junto ao Largo Carlos Amarante", Homenagem a D. Domingos Pinho Brandão, Lucerna, Porto, 1984, 179-196.

ÉtIENNE E MAYET 1984: RoBert ÉtIENNE e FrançoISE MAYET - "La dénomination antique de Mérida", LVCERNA, Porto, 1984, 159-172.

Fernandes e Ferreira 2002: S. Fernandes e R. Ferreira - "Marcas de oficina em tijolos romanos de Seilium”, Conimbriga, vol. XLI, 257-267, Coimbra, 2002, 257$-267$.

GARABITO 1978: T. GARABITO - Los alfares romanos riojanos. Produccion y comercializacion, Bibliotheca Praehistorica Hispana, vol. XVI, Madrid, 1978.

HANSEN, 1986: Jorgen Hansen - "Conduites et Plombiers de l'Ager Viennensis. Catalogue des Marques", Gallia, supp. 46 (Conduites et Objects de Plomb Gallo-Romains de Vienne (Isère), Paris, 1986, 53-185.

Helen 1975: TAPio Helen - "Organization of the Roman Brick Production in the first and second centuries A. D. An interpretation of Roman Brick Stamps", Annales Academiae Scientiarum Fennicae, 5, Helsínquia, 1975.

Hervés Raigoso 1995: Francisco M. Hervés Raigoso - "III. 7. Utensilios de iluminación doméstica e súa importación", Lucus Augusti, Urbs Romana. As Orixes da Cidade de Lugo, Concello de Lugo, Lugo, 1995, 90-92, fig. 77 (inv. 47). MaÑanes e BAlil 1974-75: MaÑanes e Alberto BALIL - Cuadernos de estudios gallegos, XXIX, Santiago, 1974-75, 303 ss.

Martins e Delgado 1989-90a: M. Martins e M. Delgado - "História e Arqueologia de uma cidade em devir: Bracara Augusta", Cadernos de Arqueologia, série II, 6/7, Braga, 1989-90 a, 11-39.

Martins e Delgado 1989-90b: M. Martins e M. Delgado - "As Necrópoles de Bracara Augusta", Cadernos de Arqueologia, série II, 6-7, Braga, 1989-90 b, 41-186; Fig. 41, n. ${ }^{\circ} 42$; Fig. 46, n. ${ }^{\circ} 45$.

Mayet 1983: Françorse Mayet - Les Céramiques Sigillés Hispaniques. Contribution à l'Histoire Économique de la Péninsule Ibérique sous l'Empire Romain, II. Planches, Dif. de Boccard, Paris, 1983.

MAYET 1984: FrançoISE MAYET - Les Céramiques Sigillés Hispaniques. Contribution à l'Histoire Économique de la Péninsule Ibérique sous l'Empire Romain, I. Texte, Dif. de Boccard, Paris, 1984.

Mezquíriz 1975: Mª A. Mezquíriz de CATALAN - "Nuevos hallazgos sobre fabricación de sigillata hispanica en la zona de Tricio, Miscelánea Arqueológica, Zaragoça, 1975, 231-243.

Morillo Cerdán 1999: A. Morillo Cerdán - "Lucernas romanas en la región septentrional de la península ibérica. Contribución al conocimiento de la implanta- 
ción romana en Hispania”, Monographies instrumentum, 8/2, vol. I e II, Éditions Monique Mergoil, Montagnac, 1999.

PAVOlini 1980: "Le lucerne in terra sigillata africana de esportazione. Proposte di una tipologia”, Colloque sur la Céramique Antique (Cartago), Actes, Cartago, 1980, 141-149.

PEACOCK 1982: D. P. S. PEACOCK - Pottery in the Roman World: an ethnoarchaeological approach, Longman Archaeology Series, Londres/New York, 1982.

Roca Roumens 1983: MERCEDES Roca Roumens - "Inscripciones decorativas en la produccion de terra sigillata hispanica de Los Villares de Andújar (Jaen)", Cuadernos de Prehistoria de la Universidad de Granada, n. ${ }^{\circ}$ 8, Granada, 1983, 433446; Est. I, n. ${ }^{\circ} 6$.

Sotomayor Muro 1977: M. Sotomayor Muro - Marcas y estilos en la sigillata decorada de Andujar, Inst. de Estud. Giennenses, Diputación Provincial, Jaén, 1977.

Sotomayor Muro, Roca Roumens e Sotomayor 1979: M. Sotomayor Muro, M. Roca Roumens e N. Sotomayor "Los alfares romanos de Andujar. Campañas de 1974, 1975 y 1977”, Noticiario Arqueologico Hispanico, 6, Ministerio de Cultura, Madrid, 1979, 441-497.

Sotomayor Muro, Roca Roumens e Fernández García 1999: M. Sotomayor Muro, M. Roca Roumens e Ma I. Fernández García - "Centro de Producción de Los Villares, Andújar (Jaén)”, Terra Sigillata Hispánica. Centro de fabricación y producciones altoimperiales, (coords. M. Roca Roumens e Mª I. Fernández García), Universidad de Jaén/Universidad de Málaga, 1999, 19-60.

WAHL 1988: J. WAHL - "Três Minas. Vorbericht über die archäologischen Untersuchungen im Bereich des römischen Goldbergwerks 1986-1987”, Madrider Mitteilungen, 1988, 29, 221-244. 


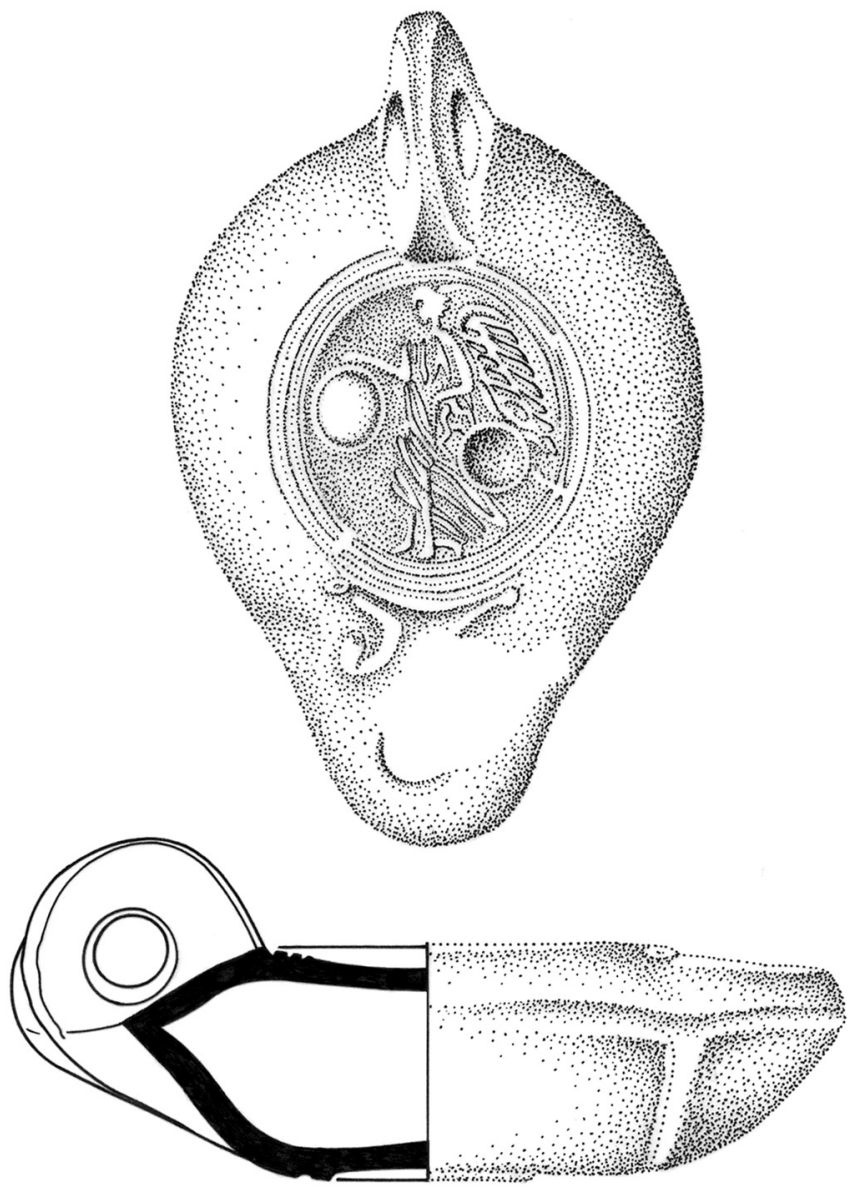

${ }^{0} \stackrel{2}{3}^{3}{ }^{2} \mathrm{~cm}$

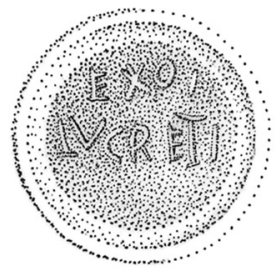



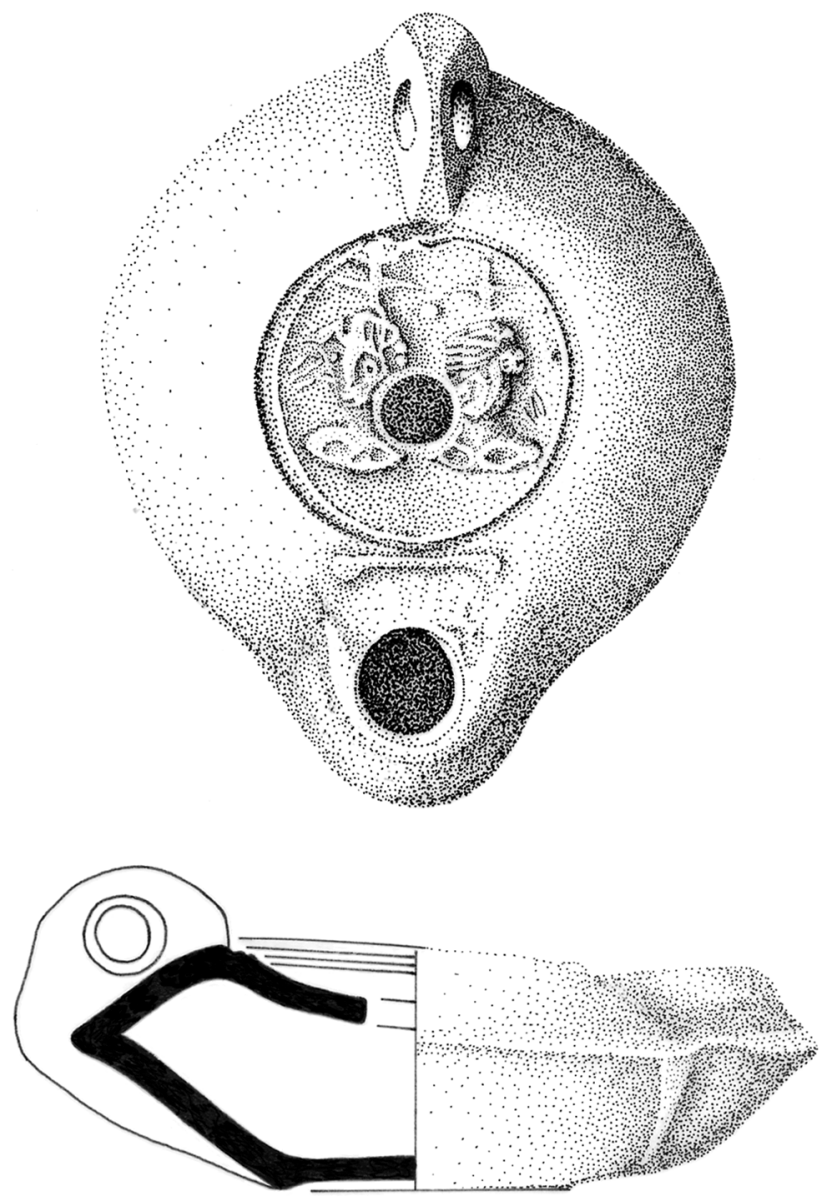

$\int^{0}{ }^{1}{ }^{3} \mathrm{~cm}$

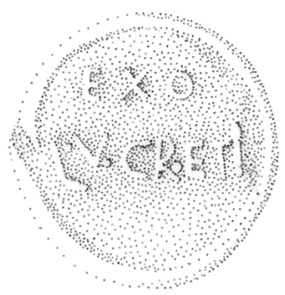



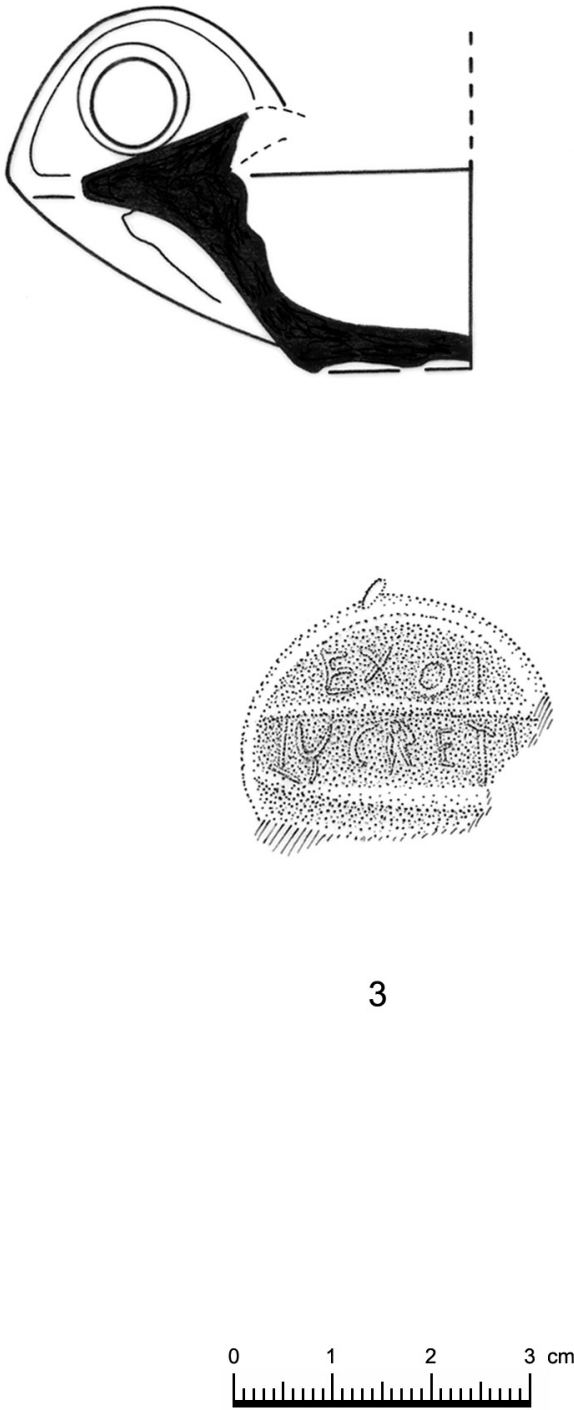


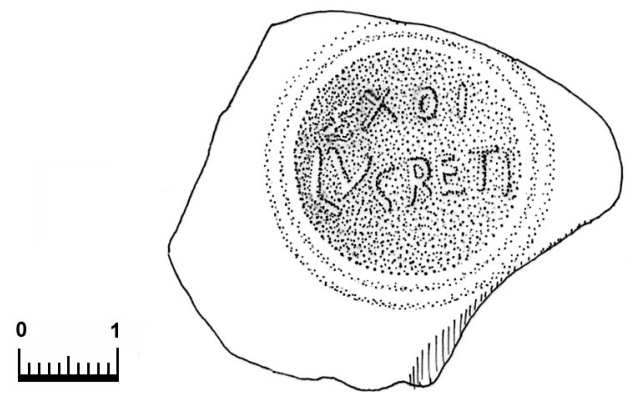

4

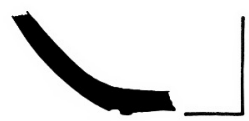

0

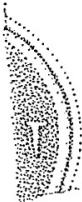



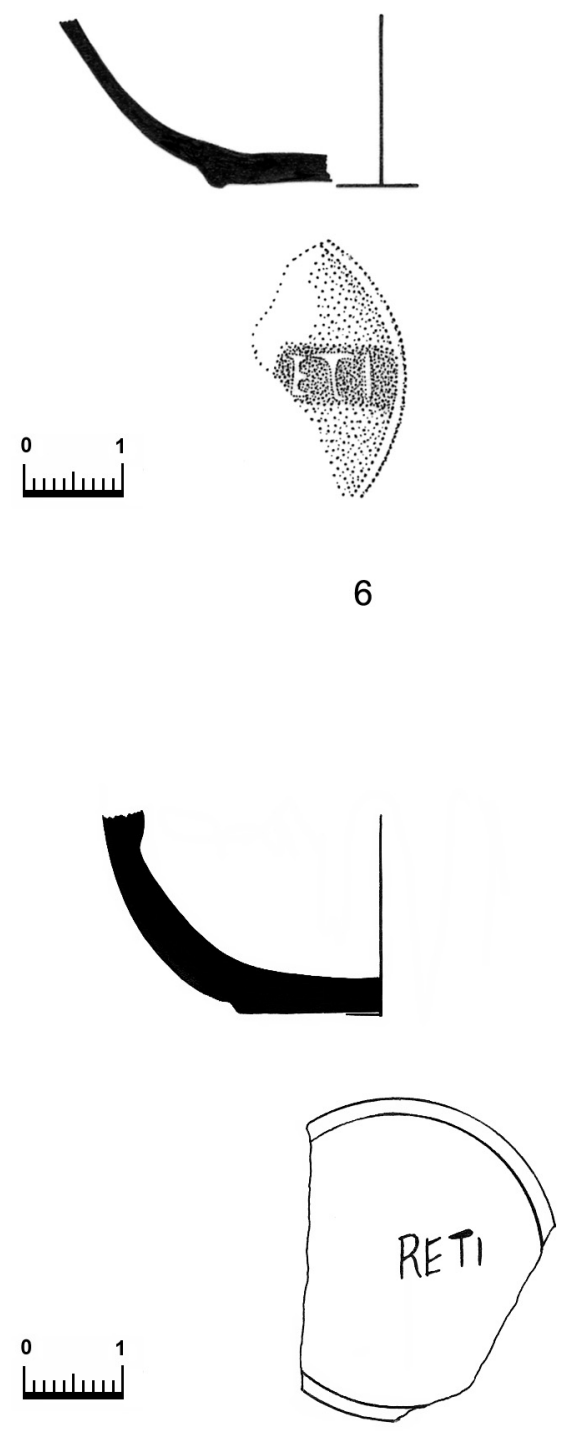

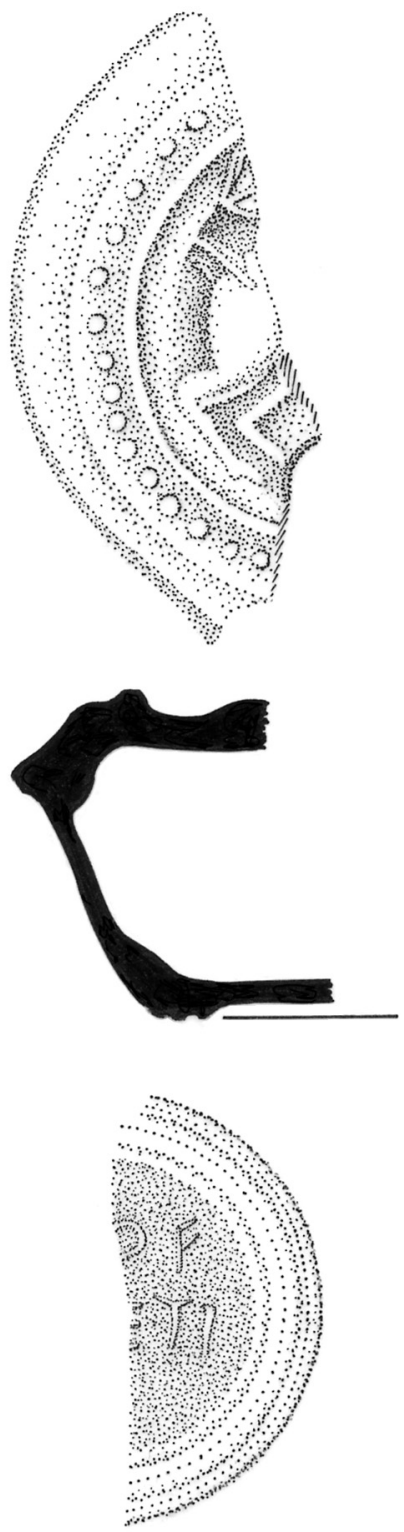

$$
0
$$$$
\text { لسبل|سا }
$$ 

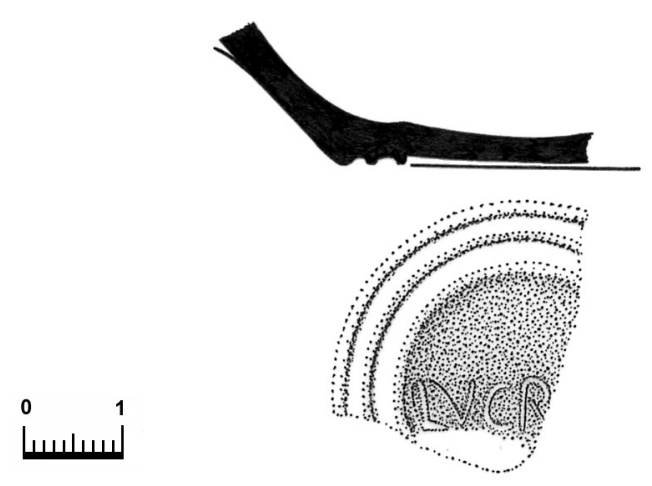

9

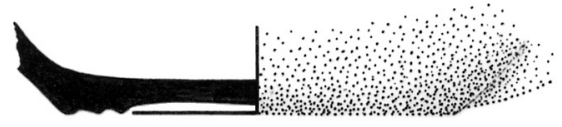

$\begin{array}{lr}0 & 1 \\ & \end{array}$

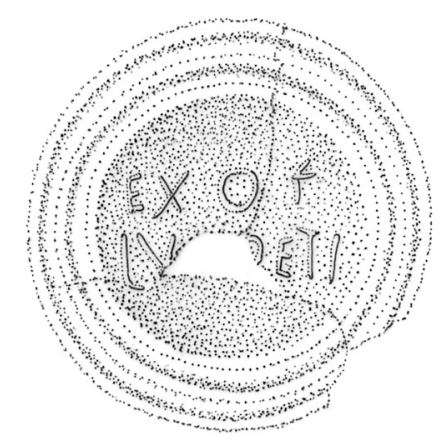




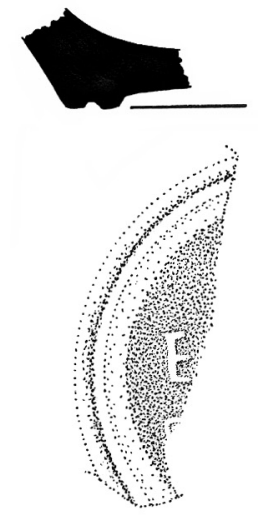

11

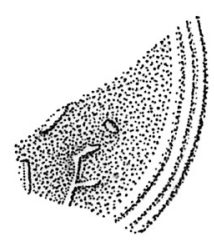

12

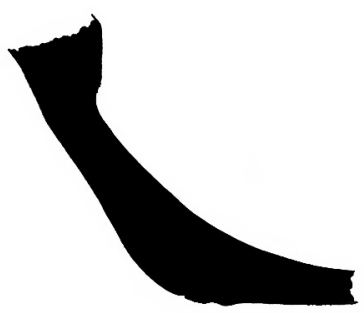

13

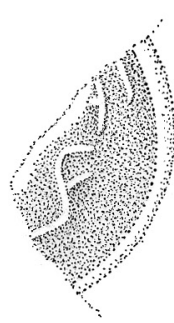

$$
\begin{aligned}
& \begin{array}{llll}
0 & 1 & 2 & 3 \mathrm{~cm}
\end{array} \\
& \text { لسسلسلسيلسيسلسلسا }
\end{aligned}
$$




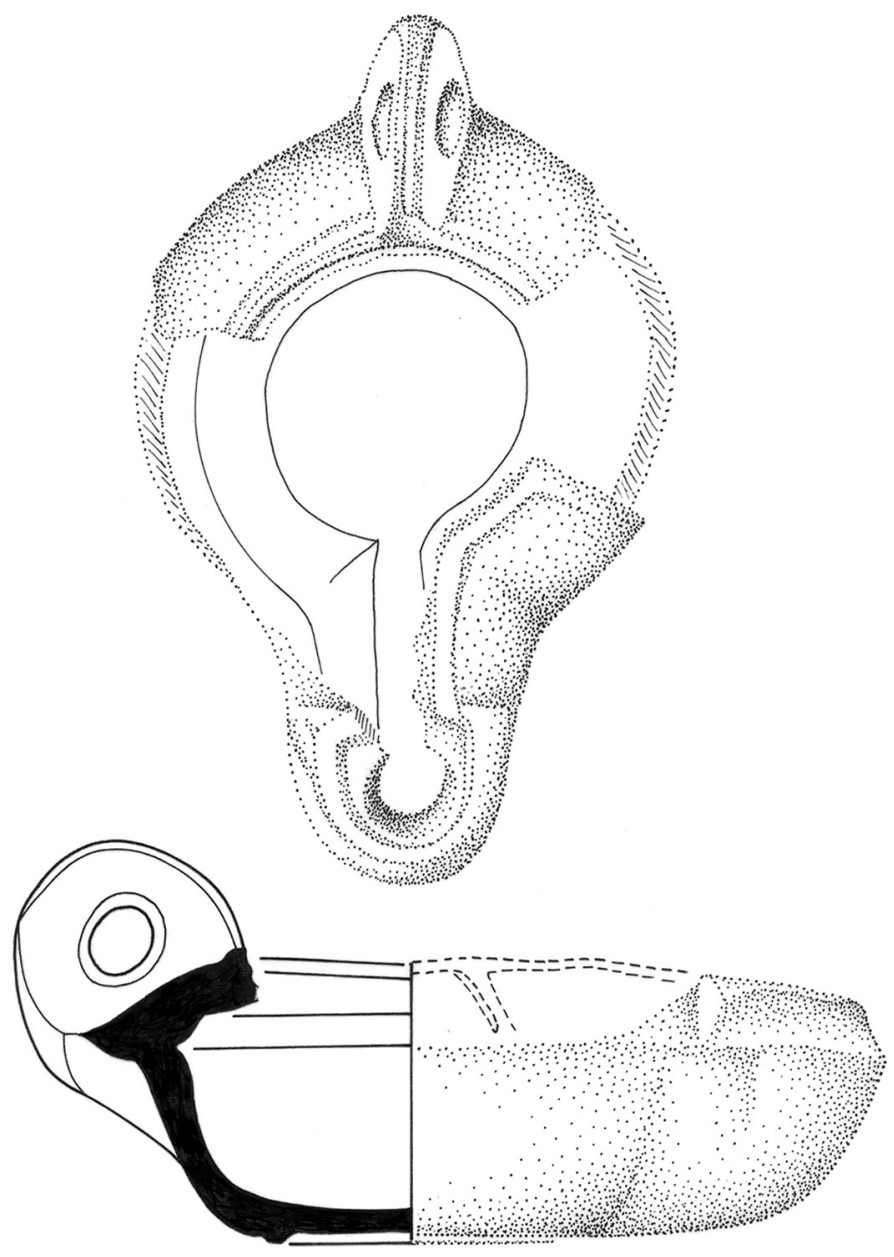

14

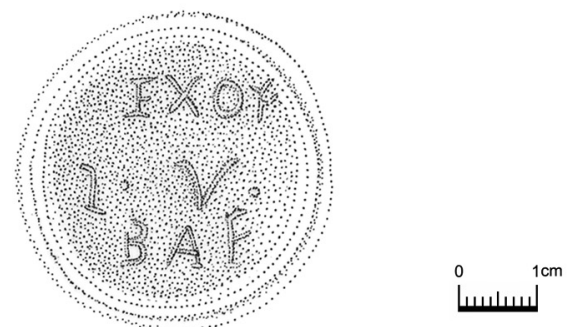



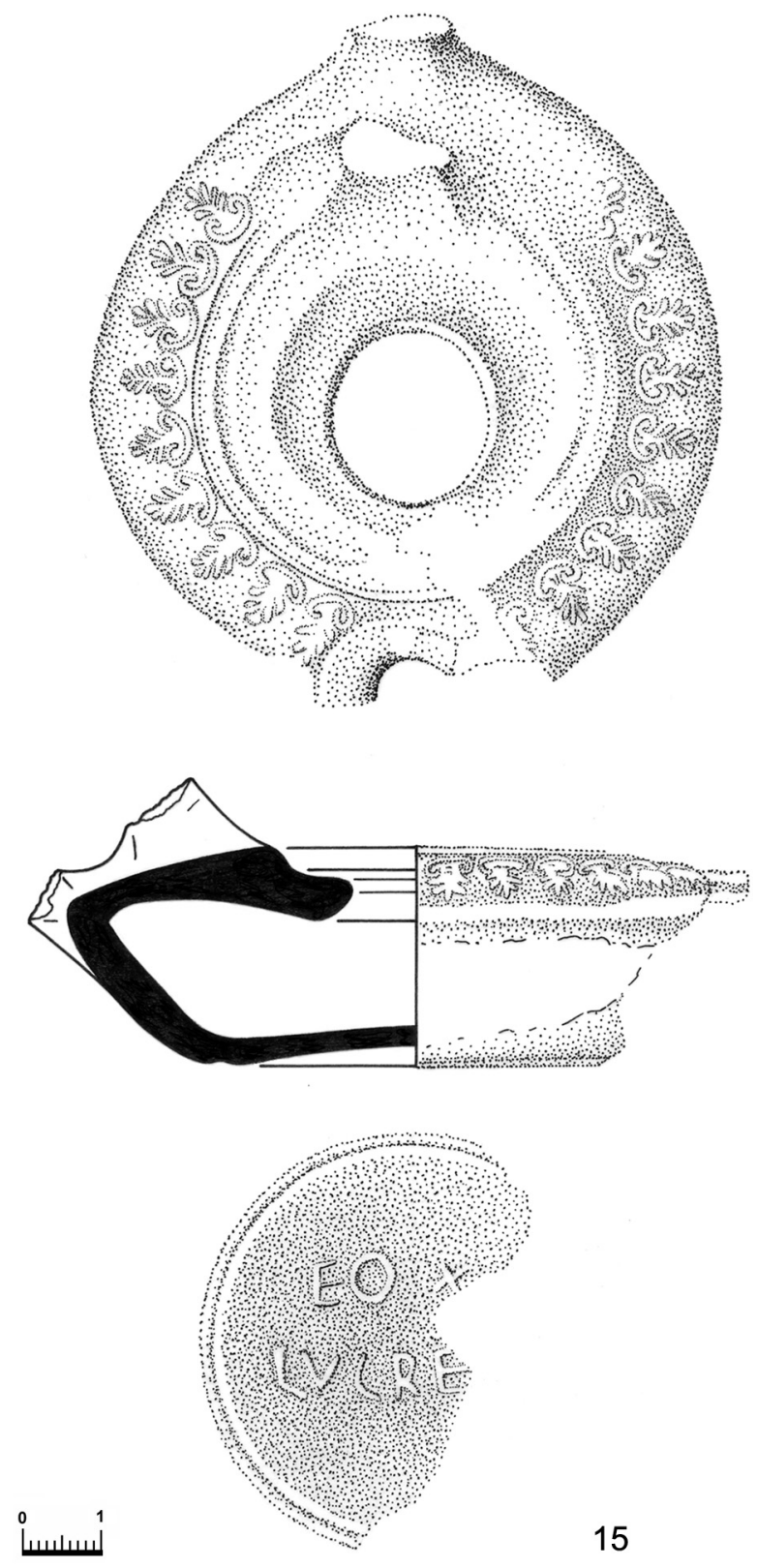

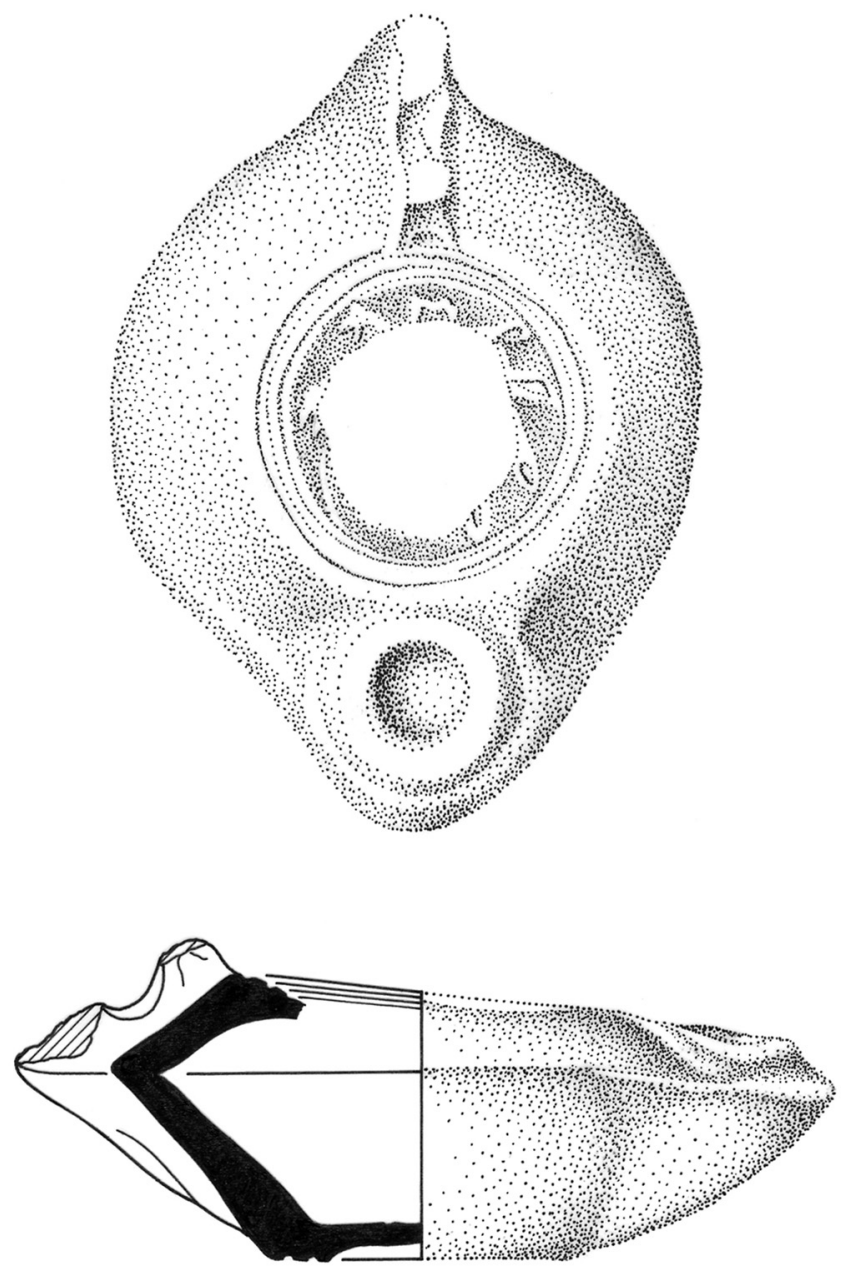

لسملسيا

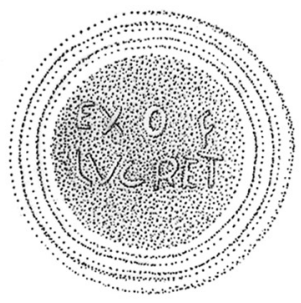



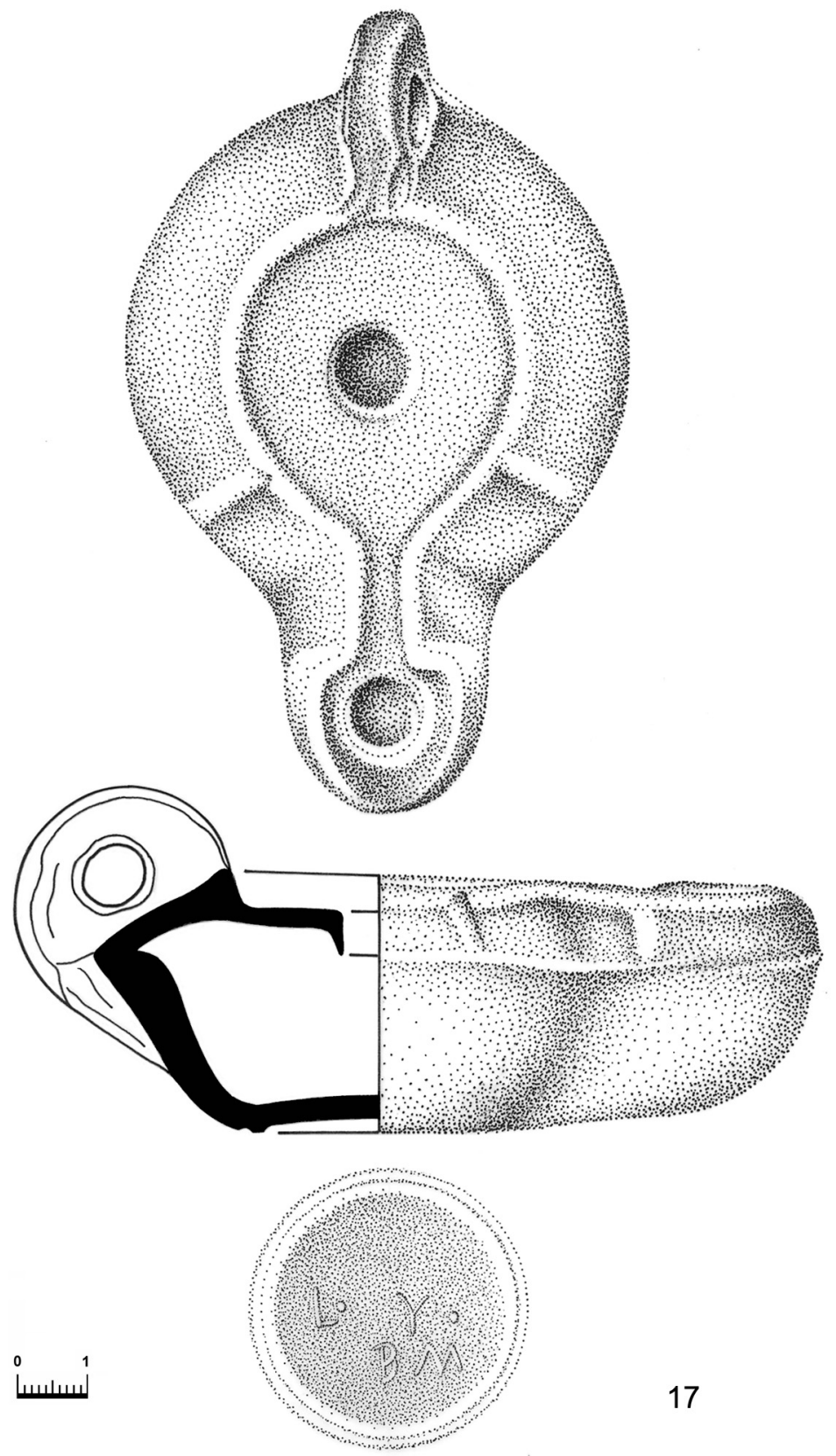